\title{
Using web-based gamified software to learn Boolean algebra simplification in a blended learning setting
}

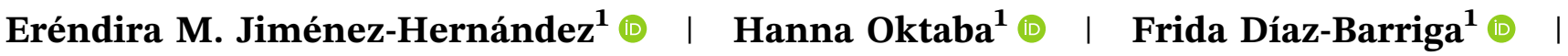 \\ Mario Piattini ${ }^{2}$
}

${ }^{1}$ Universidad Nacional Autónoma de México, Ciudad de México, Mexico

${ }^{2}$ Escuela Superior de Informática, Universidad de Castilla-La Mancha, Ciudad Real, Spain

\section{Correspondence}

Eréndira M. Jiménez-Hernández, Universidad Nacional Autónoma de México, 3000 Circuito escolar, C.U., 04510 Ciudad de México, Mexico.

Email: erendira.jimenez@ciencias. unam.mx

Funding information

Consejo Nacional de Ciencia y Tecnología (CONACYT)

\begin{abstract}
One of the fundamental topics in the education of students enrolled in computer-related degrees is that of Boolean algebra. This is because it allows the expression of several problems related to digital design, artificial intelligence, databases, compilers, and formal languages, among others, as a sequence of Boolean operations and variables, which can be dealt with by using Boolean algebra methods to optimize algorithms, minimize digital components, and so forth. This study presents a piece of web-based software, denominated as MiniBool, which has been developed with the objective of supporting the learning of Boolean algebra in a blended learning setting. This educational proposal gives students the opportunity to reinforce learning at any time and in any place. It additionally increases the learners' motivation by including gamification, through the use of a ranking that shows the students' level of participation. MiniBool was evaluated by means of a formal experiment, which was carried out with Discrete Mathematics students at a higher education institution in Mexico, where two groups were formed randomly: A control group, whose members attended classes and reinforced their knowledge in a traditional manner with a pencil and paper, and an experimental group, which learned in a blended learning context, receiving the same classes as the control group, but reinforcing what they had learned using MiniBool. The statistical results obtained indicate that the use of MiniBool has a positive and motivating effect on learning and that a greater academic performance is achieved than when the traditional teaching-learning method is applied.
\end{abstract}

\section{K E Y W O R D S}

blended learning, Boolean algebra, education, gamification, web-based education

\section{1 | INTRODUCTION}

Boolean algebra (BA) is an algebraic structure in which there are only two possible values for a variable: "true" or "false," which are often expressed as " 1 " and " 0 ," respectively. BA was first used to simplify logic circuits in electronic components [70], but is now employed in various areas, such as, to encrypt information via a network [55], to detect and classify attention deficit hyperactivity disorder [80], in database normalization [69], to find the shortest route in an undirected graph in as little time as possible [66], and to improve the security of CAPTCHA tests [38]. It is not, therefore, surprising that BA is a fundamental subject for students on degrees related to computing. 
Unfortunately, the teaching of BA is a challenge, as stated in References [2,24], there are various problems related to the understanding of Boolean variables and expressions. A lack of motivation and dedication on the part of undergraduate students as regards tackling the subject of BA has also been noted [63]. This may be partially owing to the fact that today's students, unlike prior generations, frequently use computer games, social networks, and technologies, and this has modified the way in which they spend their leisure time, and how they research and learn [17]. The aforementioned situation has motivated the development of a solution to this problem, which is based on Blended Learning (BLearning), that is, combining the traditional form of faceto-face classes with the use of technology [15]. A piece of web-based software denominated as MiniBool has, therefore, been developed to support the process of teaching-learning of the simplification of Boolean functions for students on computer-related degrees, in a B-Learning setting.

Minibool allows the simplification of Boolean functions, both user-defined and generated by the software itself (software-generated expressions), which can be expressed as truth tables, Karnaugh Maps (K-Maps), Boolean functions (in miniterms and maxterms), and nonstandardized functions. Moreover, it includes gamification by means of a ranking that shows the students' level of participation to motivate and speed up their learning. Likewise, MiniBool allows professors to both monitor their students' learning and communicate with them.

This educational tool has been tested with students on the Computer Systems Engineering (CSE) degree at a higher education institution in Mexico by means of a formal experiment, which consisted of comparing two groups in a discrete mathematics (DM) class. One of these was the control group, whose members learned in face-to-face classes and reinforced their learning in the traditional manner, using a pencil and paper to solve a list of problems provided by their professor in and outside the classroom. The other was an experimental group, whose members learned in the same face-to-face classes, but who reinforced their learning both in and outside the classroom using MiniBool to resolve the problems that the professor had given them and those set out by the students themselves.

The specific objective of this study was to answer the following research questions (RQ):

RQ1: When learning to simplify Boolean functions, does students' academic performance improve if they are taught using a blended learning method incorporating the MiniBool software rather than the traditional learning method?
RQ2: When learning to simplify Boolean functions, does students' level of motivation increase if they are taught using a blended learning method incorporating the MiniBool software rather than the traditional learning method?

The remainder of this study is organized as follows. Section 2 shows the related work, while Section 3 describes the DM course. Section 4 provides a brief summary of BA and Section 5 presents the web-based gamified software, MiniBool. Section 6 shows the study design, the materials, and the procedure employed to evaluate learning and motivation, whereas Section 7 contains the results of the statistical analysis of the evaluation of learning and motivation. Section 8 provides an evaluation of the validity of the formal experiment carried out, whereas Section 9 contains the findings and a discussion. Finally, Section 10 presents our conclusions and future work.

\section{2 | RELATED WORK}

\section{1 | Software proposals for learning BA simplification}

To support the teaching-learning process of the simplification of Boolean functions, we have identified and analyzed the following technology-based proposals: (a) the CAD package [34], an educational software that can be used to minimize logic functions to learn digital design, (b) WinLogiLab [20], a set of tutorials, whose objective is to achieve an initial understanding of digital logic design, (c) Karnaugh Map Analyzer [36], a desktop application, whose purpose is the simplification of K-Maps and Boolean expressions, (d) the game-based proposal from Reference [8], which is used to learn to minimize Boolean functions using K-Maps, (e) Simple Solver [73], a desktop application with which to learn Boolean equations, logic gates, and flipflops, (f) Boolean Expression Calculator [6], a calculator, which is used to simplify Boolean expressions, and (g) Karnaugh Minimizer [37], a program that facilitates the minimization of Boolean functions. We also kept in mind the experience acquired with Boolean Soft [30], the first effort made by one of the authors of this article to reinforce learning of the Boolean expressions simplification.

After analyzing the related studies (Table 1), we realized that it was necessary to construct MiniBool because the majority of the existing tools had been designed to be employed as desktop applications for Windows, which limited their use. It was for this reason that we opted for a web-based design that would allow the proposal 


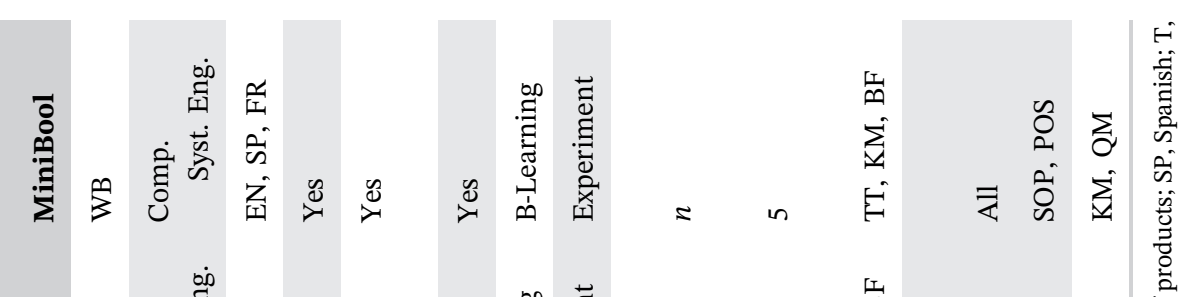

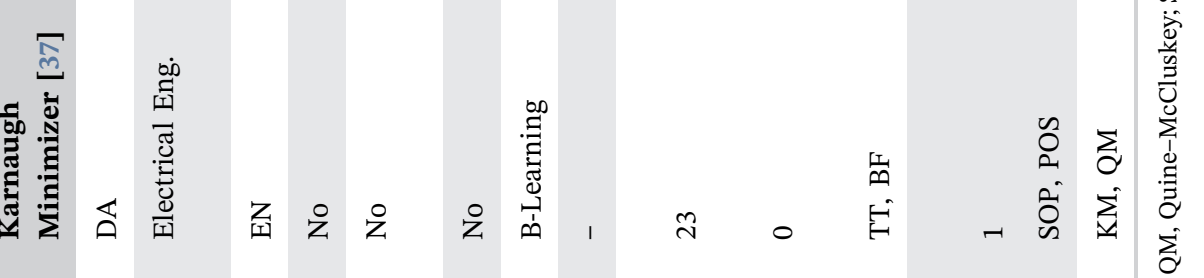

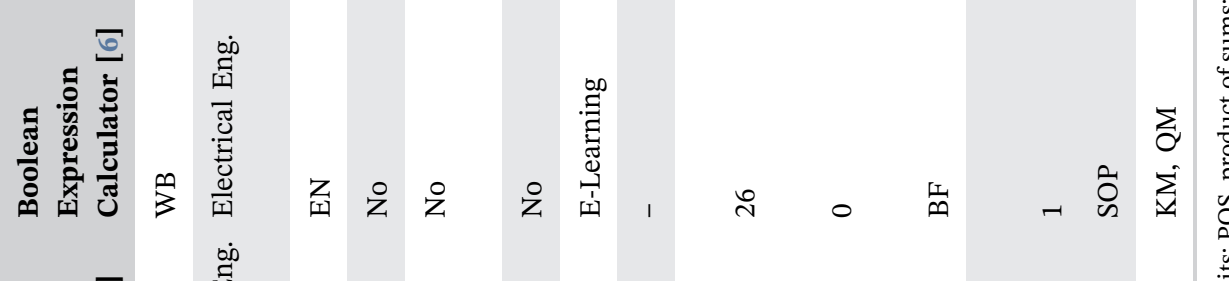

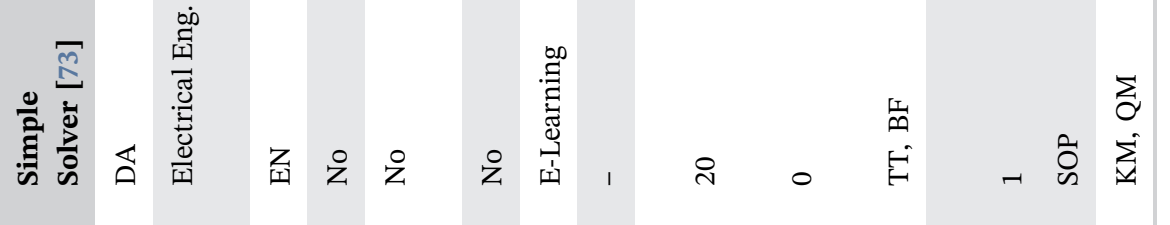

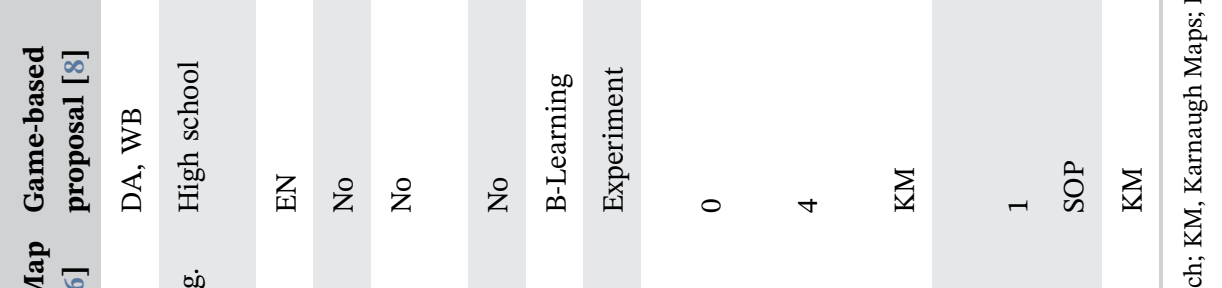

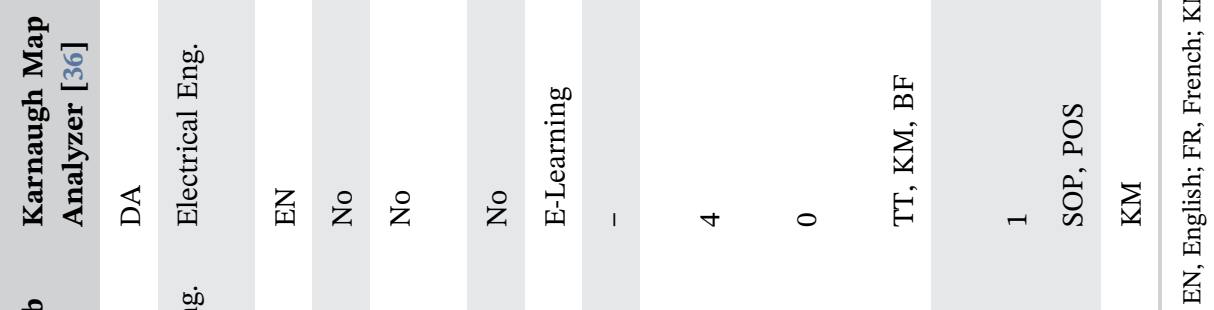

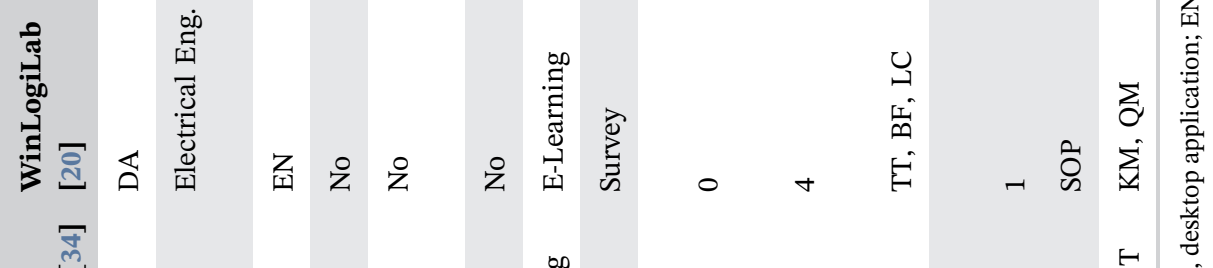

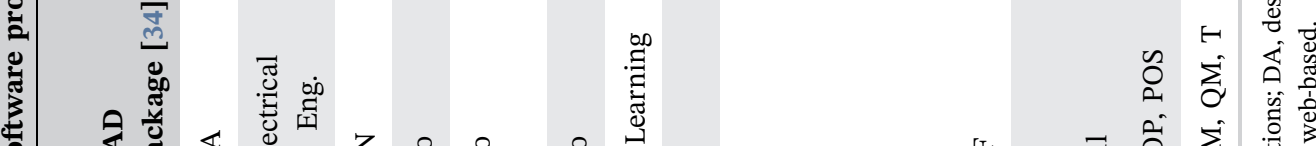

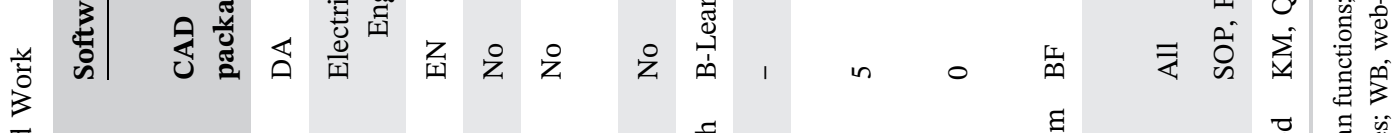

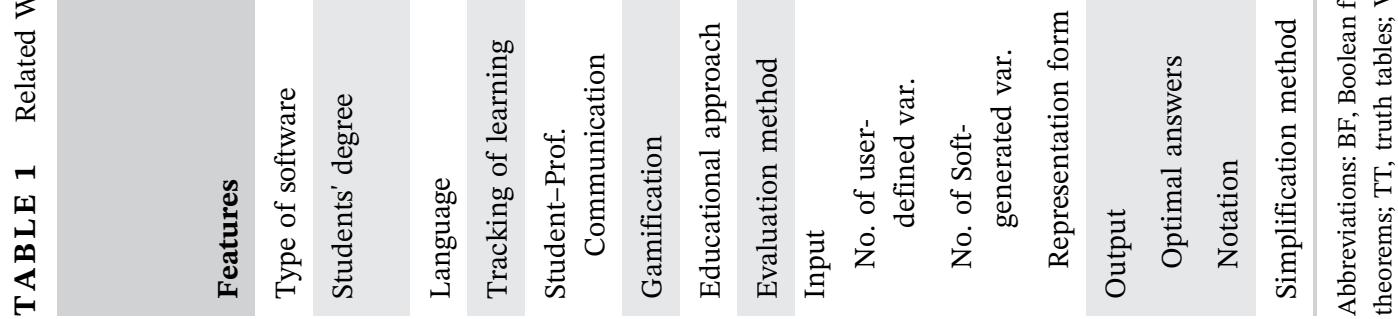


presented in this paper to be used with any device connected to the Internet, independently of its operative system. We also realized that the majority of the proposals had been developed to be used by Electrical Engineering degree students with the intention of teaching them the concept of digital circuits and that these proposals did not, therefore, have the generic focus required by students on BS Computing degrees. Similarly, we discovered that the majority of proposals were available only in English, which would be a limitation for anyone who did not speak that language. This aspect was consequently kept in mind when designing MiniBool, which is available in English, Spanish, and French.

Moreover, the related studies found do not allow professors to follow their students' progress, signifying that professors do not have information with which to verify whether any of their students are having difficulties in learning. This does not occur with MiniBool, which presents statistics and detailed information regarding students' participation. Furthermore, none of the studies found included mechanisms that would facilitate communication between professors and their students, whereas this element is included in MiniBool.

With regard to input information, MiniBool can work with Boolean functions with $n$ number of variables when they are user-defined, and up to five variables when they are randomly generated by the software itself, thus exceeding the number of variables permitted in the related studies. Moreover, the input information can be expressed in several ways, such as truth tables, K-Maps, Boolean functions (in miniterms and maxterms), and nonstandardized functions. Furthermore, and with regard to the output, MiniBool employs two Boolean expression simplification methods (K-Map and McCluskey) to allow the calculation of all optimal answers, which can be expressed as both the sum of products (SOP) and the product of sums (POS).

\section{2 | Gamification}

The term "gamification" refers to the use of game mechanics in nongame contexts [31,56], which are employed with the objective of increasing the user's participation [32], therefore, it has been used in several areas, such as in marketing [25], health [86], and education [18].

The gamification of learning makes it possible to increase motivation and engagement by capturing the students' interest and inspiring them to continue learning [60], thus improving their absorption and retention of knowledge [33], and providing immediate and meaningful feedback that will help them adjust their performance [28]. It has, therefore, been used in the teaching- learning process of several different contents, with positive results $[14,26,59]$, and it is for this reason that we have included gamification in the design of MiniBool. This element is not found in any of the related studies presented in Table 1.

According to Vassileva [84], there are four types of gamification: (a) Gamification based on ownership, when the user can obtain badges; (b) gamification based on missions, when the user is able to access a restricted area or section; (c) gamification based on achievements, when the user can acquire additional skills or functionalities, and (d) gamification based on status when the user can attain a certain level or place in a ranking. This last type was selected for MiniBool and was implemented by means of a ranking that shows the students' level of participation based on points. The selection of the type of gamification was determined by considering the evaluation conducted by Smiderle et al. [74], in which it was found that the competition caused by rankings can increase the learners' level of engagement and can consequently have a constructive effect on participation and learning, especially with extroverted individuals who tend to be active, enthusiastic, sociable and eloquent. It was also discovered that a gamified self-tracking approach should be incorporated to take introverted individuals into consideration, and self-tracking has, therefore, been incorporated into MiniBool. We similarly considered the evaluation carried out by Jia et al. [27], in which it was found that gamification based on points provides a broad spectrum of users according to the Big Five Personality Factors model [50], obtaining the highest-rated motivational type according to the four perceptions that were measured: Enjoyable, reliable, helpful, and usable.

Nonetheless, gamification based on points, which is denominated as "pointsification" [22], implies exploring the educational approach to be implemented to avoid distracting learners from the learning objectives [21] and preventing disengagement and confusion [43]. We have, therefore, adopted a manipulative approach [44] during the gamification of MiniBool, as "manipulation involves practicing a task and exercising a routine, which increases the degree of experience. Over time, experience increases the expertise of the student. Therefore, manipulation is associated with the following characteristics: Practice, execution, and experience" [29].

\section{3 | Blended learning}

B-Learning is an educational approach that combines technology-mediated learning, aka Electronic learning 
(E-Learning), with the traditional method (face-to-face) [89]. This makes it possible to increase the learner's intrapersonal and socioemotional knowledge, in addition to improving the students' relationship and coexistence with their teacher, classmates, and environment [5,45]. B-Learning has three principal approaches [64]: (a) The theoretical approach, in which the student is provided with the contents and materials in text documents; (b) the multimedia approach, in which the student is provided with the contents in the form of videos and recordings, and (c) the experimental approach, which allows the student to acquire practical knowledge by means of software with emulators, simulators, and so forth.

B-Learning has been proven to have positive effects on students' satisfaction in different areas of learning $[71,88]$. It is for this reason that a B-Learning setting with an experimental or practical approach has been employed in some of the related studies $[8,30,34,37]$ and in MiniBool, with the objective of reaffirming the knowledge acquired in classes, thus avoiding the problems of communication, association, and teamwork reported in Reference [81] when only a technology-mediated approach is employed.

\section{3 | DM COURSE}

\section{1 | Course description}

This course is part of the subjects in the curriculum taught in the first semester of the CSE degree at the National Technological Institute of Mexico (TecNM), on the Technological Institute of Morelia (ITM) campus [78]. The ultimate goal of the course is to enable students to infer and develop mathematical models aimed at solving problems in the area of Computer Science.

The course is organized into six learning units, which are addressed sequentially. These are (a) Numeral systems, (b) sets, functions, and relations, (c) mathematical logic, (d) Boolean algebra, (e) graph theory, and (f) trees.

\subsection{BA unit}

This study focuses on the BA unit. The main learning objective of this unit is to enable students to apply the principles of BA to simplify Boolean functions. The specific competencies (SC) that the unit aims to develop are:

$\mathrm{SC} 1$ : The capacity to represent Boolean expressions using truth tables and mathematical symbols.

SC2: The capacity to simplify Boolean functions by applying Boolean algebra theorems.
SC3: The capacity to simplify Boolean functions by applying K-Maps.

SC4: The capacity to simplify Boolean functions by applying Q-Mc method.

SC5: The capacity to obtain and simplify Boolean expressions from logic circuits.

The aforementioned capabilities will allow students to develop the following generic competences: The ability to work with the concept of abstraction, analysis and synthesis, organizational and planning skills, the resolution of problems, critical thinking, creativity, and decision-making.

\subsection{Instructional design}

Instructional design is the practice of creating instructional experiences with which to support the development and acquisition of knowledge and skills [51]. There are many instructional design models, of which we decided to select the ARCS model to create a learning environment geared towards stimulating and maintaining students' motivation.

ARCS is an instructional model that was developed by John Keller and which focuses on motivation [39,41]. The analysis of motivational needs and the corresponding selection of tactics are based on four dimensions of motivation. These dimensions were derived from a synthesis of research on human motivation and are known as Attention (A), Relevance (R), Confidence (C), and Satisfaction (S), or ARCS. Numerous reports and studies in more than 50 countries have described and confirmed the validity of this model [42].

The instructional design for the DM course was, therefore, created by the researchers of this paper and the professor of the subject, focusing the efforts of the teaching-learning process on attaining and holding students' attention (A), showing students the usefulness of the content $(\mathrm{R})$, convincing students that they can succeed in learning (C) and making students proud of what they have learned (S). The main supporting motivational and learning strategies that were designed for each component and subcomponent of the ARCS model are shown in Table 2.

\section{4 | BOOLEAN ALGEBRA}

BA was first published by George Boole in 1854, in the book entitled "An Investigation of the Laws of Thought". BA is a set of rules, laws, and theorems that can express logic operations in a mathematical manner [47]. Many problems in digital design, mathematical logic, artificial 
TABLE 2 Main motivational and learning strategies

\begin{tabular}{|c|c|c|}
\hline Component & Subcomponent & Main supporting strategies \\
\hline \multirow[t]{3}{*}{ Attention } & Perceptual arousal & - Real-world examples: Using examples from everyday life. \\
\hline & Inquiry arousal & - Inquiry: Asking students questions to allow them to think critically. \\
\hline & Variability & $\begin{array}{l}\text { - Variety of methods with which to present material: Using videos, diagrams, tables, figures, } \\
\text { pictures or other visual aids to sustain interest. }\end{array}$ \\
\hline \multirow[t]{3}{*}{ Relevance } & Goal orientation & $\begin{array}{l}\text { - Perceived present worth: Explaining why and how the content helps students in the present. } \\
\text { - Perceived future usefulness: Explaining why and how the content will help students in the } \\
\text { future. }\end{array}$ \\
\hline & Motive matching & $\begin{array}{l}\text { - Modeling: Including exercises, anecdotes, and examples that illustrate the content to achieve } \\
\text { personal goal setting. }\end{array}$ \\
\hline & Familiarity & $\begin{array}{l}\text { - Link to previous experience: giving students a sense of continuity by allowing them to establish } \\
\text { connections between new information and what they already know. }\end{array}$ \\
\hline \multirow{2}{*}{ Confidence } & $\begin{array}{l}\text { Success } \\
\text { opportunities }\end{array}$ & $\begin{array}{l}\text { - Facilitate self-growth: Giving students the opportunity to be successful by providing experiences. } \\
\text { - Provide feedback: Giving students feedback about their improvements and deficiencies during } \\
\text { the learning process, thus allowing them to adjust their performance. }\end{array}$ \\
\hline & Personal control & $\begin{array}{l}\text { - Learner control: giving students a sense of control over their learning and assessment, thus } \\
\text { allowing them to believe that their success is a direct result of the amount of effort they have put } \\
\text { into their learning. }\end{array}$ \\
\hline \multirow[t]{2}{*}{ Satisfaction } & $\begin{array}{l}\text { Intrinsic } \\
\text { reinforcement }\end{array}$ & $\begin{array}{l}\text { - Continuing motivating: including enthusiastic comments in the materials or in the feedback, } \\
\text { which reflect positive feelings. }\end{array}$ \\
\hline & Extrinsic rewards & - Motivational feedback: Recognizing students' achievements with verbal praise. \\
\hline
\end{tabular}

intelligence, databases, compilers, and formal languages can be defined as a sequence of Boolean operations and variables [46]. For example, upon simplifying a logic function, it is possible to reduce the original number of gates required in the employment of digital circuits, which reduces the size and the production costs, thus increasing velocity [47].

It is said that the minimum expression for a logic function is that which has the smallest possible number of terms, along with the smallest possible of literals [67]. One method that is commonly used to simplify logic expressions consists of the use of laws, theorems, and axioms of the BA [4]. This simplification with the use of theorems and postulates of BA is effective; however, the main drawback of this type of simplification involves the correct application of BA laws [35]. This problem of minimizing a Boolean function using theorems can be solved with the help of a Karnaugh Map (K-Map) [1], which was proposed in 1953 by Maurice Karnaugh, in his work "The Map Method for Synthesis of Combinational Logic Circuits" as a graphic method by which to simplify Boolean functions.

A K-Map is, therefore, a table containing $2^{n}$ cells, where $n$ represents the number of different variables in the Boolean expression that it is necessary to simplify
[35]. In a K-Map, each of the terms of a Boolean function is represented with a "1" [1]. To simplify the logic expressions, it is necessary to group the information from the K-Map in blocks of adjacent 1 s in: $1,2,4,8 \ldots 2^{n}$ elements [75]; the larger the blocks in which the information is grouped, the simpler the resulting Boolean expression is, as it will have fewer literals. The simplified Boolean expression that is obtained by grouping the $1 \mathrm{~s}$ of the cells is known as the "Sum Of Products" (SOP). In the $\mathrm{K}-\mathrm{Map}$, if a cell does not have a " 1 ," then it has a "0," given that there are only two possible values; the 0s make it possible to obtain the simplified Boolean expression in the "Product Of Sums" (POS) [23].

The K-Map method is illustrative and efficient. It is, however, limited to situations in which the Boolean function to be simplified has a maximum of six variables [8]. This motivated the mathematician and philosopher Willard van Orman Quine to propose, in 1955, variants of the K-Map; these variants consisted of comparing bit strings to group those strings that were different as regards only one bit, but supported by the properties of logic: $p+p^{\prime}=1$ and $p+p q=p(1+q)=p$ [65].

In 1956, E. J. McCluskey created the tabular method to simplify Boolean expressions containing more than six 
variables, in which each of the elements obtained with the method was denominated as a Prime Implicant (PI) [49]. The Quine-McCluskey (Q-Mc) method, therefore, simplifies Boolean functions, as occurs with the K-Map method [56], but it determines all the possible PIs (or simple terms) of the simplified function, of which not all of the simple terms should form part of the function, given that some of them are redundant [72]. The response obtained by using the Q-Mc method and eliminating the redundant PIs, can be optimized through the method developed by Stanley R. Petrick [62]. It is necessary to keep in mind only that, as the PIs grow, so does the probability of various optimum responses, which exponentially increases the iterations to obtain the optimum response(s) [82].

\section{MINIBOOL}

MiniBool is an educational software that was designed to reinforce the knowledge related to the simplification of Boolean functions. The specific competencies that students should be able to develop with MiniBool are SC1, $\mathrm{SC} 2, \mathrm{SC} 3, \mathrm{SC} 4$, and SC5 partially, as students can simplify the Boolean expression of a logic circuit but without its graphic representation.

This tool allows the simplification of Boolean expressions of $3,4,5, \ldots n$ variables, which can both be specified by the student (user-defined) and randomly created by the software itself (software-generated). In the case of user-defined functions, the input information can be expressed in three ways as truth tables, K-Maps, or Boolean expressions. When a Boolean function is entered as a truth table, or as a K-Map, the True values should be indicated in the corresponding cells with a " 1 ," or with a " 0 " if they are False, as shown Figure 1. MiniBool also allows the student to type a Boolean function in a text box by means of a mathematical expression, which can be denoted as an SOP, a POS, or in a generalized manner, that is, it does not matter whether or not it is in parenthesis or whether those parentheses are affected by the complements.

In the case of software-generated functions, MiniBool randomly generates the True or False values that the Boolean function to be simplified should have. For example, if three variables are integrated into one Boolean function, its truth table will be made up of $2^{3}=8$ cells, in which each cell will have a random value. This gives the student the opportunity to resolve not only the problems proposed by the professor but also those randomly set out by MiniBool.

Once the Boolean function has been introduced using one of the aforementioned ways, MiniBool shows the truth

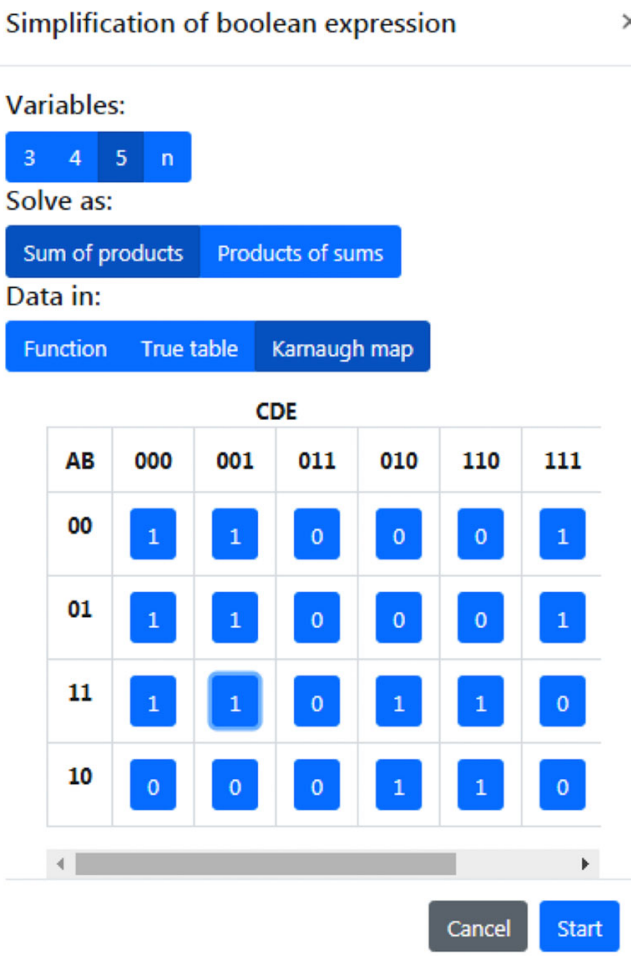

FIG URE 1 Example of one Boolean function entered as a K-Map in the software

table, the K-Map, and the equivalent Boolean expression, and asks the student to introduce the response of the simplified Boolean function, which should be solved by employing one of the appropriate methods (BA laws, K-Map, or Q-Mc). After the response has been sent (Figure 2), MiniBool provides all the optimum simplified solutions to that Boolean function (because many BA problems have more than one optimum simplified function).

Upon placing the mouse on the correct response that the software has provided, MiniBool shows the information on the K-Map used to obtain a specific term. MiniBool allows the simplification of $n$ variable expressions, although it is necessary to keep in mind that the Q-Mc method requires (in the worst-case scenario) $2^{n}$ iterations to find the PIs and, given that the not all of them should form part of the simplified Boolean expression, it is necessary to select only those elements that completely describe the Boolean model with the fewest number of variables, and this is done using the Petrick's method [62]. The number of iterations that MiniBool has to carry out is of a factorial nature because all possible responses are obtained by comparing the different PIs, and the computer's memory may, therefore, not be sufficient in some cases.

This software-based educational tool provides the learner with a sense of achievement and is error-tolerant. In this context, when a student does an exercise, 

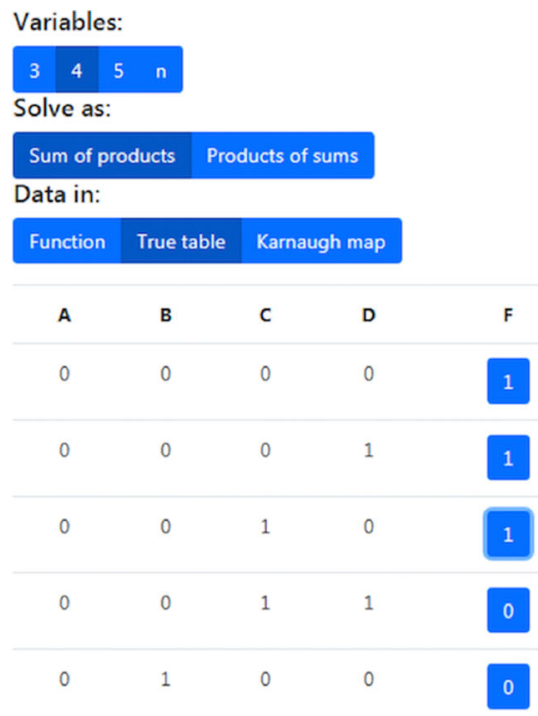

CD

\begin{tabular}{|c|c|c|c|c|}
\hline AB & 00 & 01 & 11 & 10 \\
\hline 00 & 1 & 1 & 0 & 1 \\
\hline 01 & 0 & 1 & 0 & 1 \\
\hline 11 & 1 & 1 & 1 & 0 \\
\hline 10 & 0 & 1 & 0 & 1 \\
\hline
\end{tabular}

Write your answer:

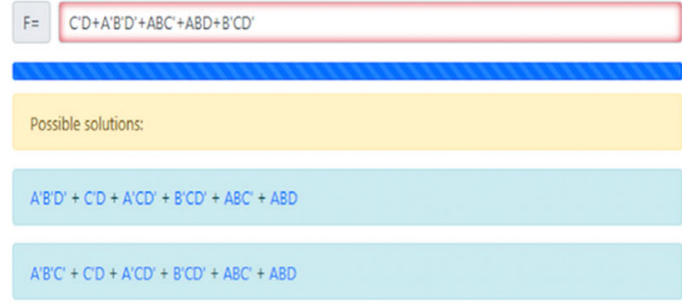

F I G URE 2 Example of exercise carried out by the student with the correct response provided by the software

MiniBool provides immediate feedback, thus allowing the student to discover whether the response is correct or incorrect. If it is correct, the student obtains points, which depend on the complexity of the problem resolved, and this is determined by two main factors: The type of problem (user-defined or software-generated) and the number of variables $(3,4,5$, or $n$ variables). The student can see how many points have been obtained, along with his/her place in the ranking, in which the other students' points appear (Figure 3). MiniBool, therefore, incorporates gamification to speed up the learning process

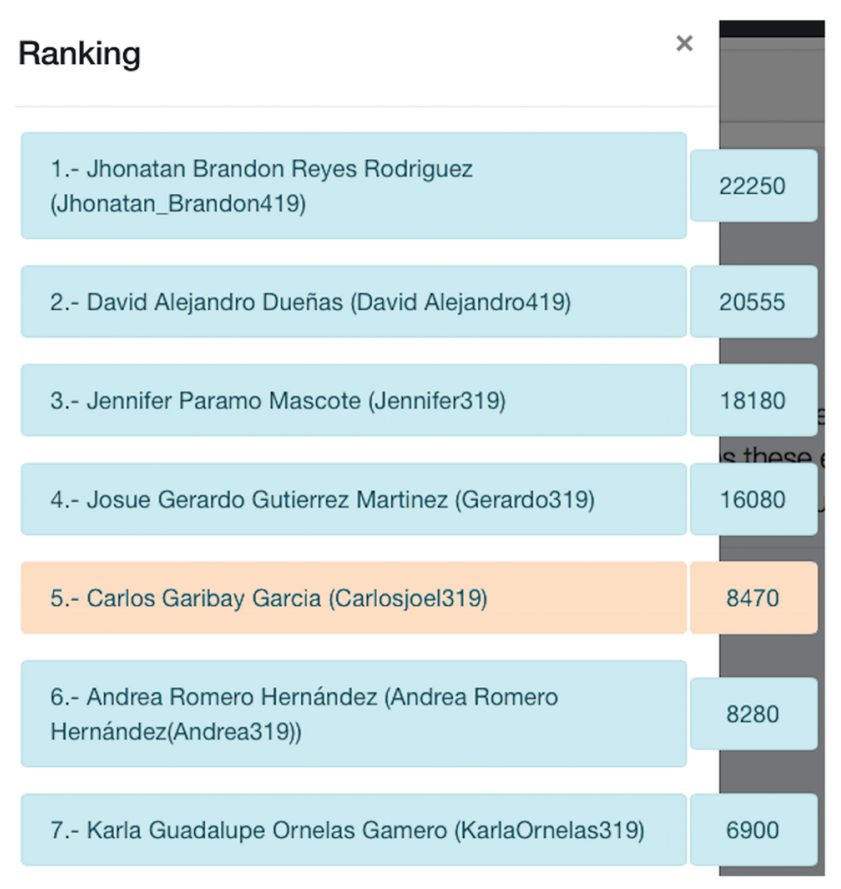

F I G U RE 3 Ranking of MiniBool
[85], improve the retention of information [7], and increase the students' motivation to learn [16].

As MiniBool has been designed as a support instrument for a B-Learning setting, the software allows the students and professors to communicate by means of messages. The system also generates statistics regarding the students' participation, with the intention of making it easier for the professor to follow the students' learning. As MiniBool is web-based, it can be executed on any computer or mobile device that has access to the Internet, thus making it easier for the student to learn in any place and at any time. Finally, MiniBool is available in English, Spanish, and French [52].

\section{6 | METHODS}

\section{1 | Study design}

The learning attained using the web-based gamified software described herein was evaluated and compared by means of a formal experimental design called the pretest/posttest randomized control group [9], which allowed us to statistically compare the differences between a control group (CG) and an experimental group (EG) [12].

Two written examinations were applied in the experiment. The first was a diagnostic examination (pretest), which was given to both the CG and the EG before the experimentation and was used to evaluate the participants' prior knowledge as regards the simplification of Boolean expressions. The second examination (posttest) was also given to both groups with the objective of evaluating the knowledge that they had acquired after the 
experimentation. This allowed us to simultaneously compare the differences between the results obtained by the members of the CG (who employed the traditional learning method, reinforcing their learning with exercises using a pencil and paper) and those obtained by the members of the EG (who employed the traditional learning method, but whose learning was reinforced with exercises using MiniBool). The participants in both groups were selected randomly.

\section{2 | Materials}

The written diagnostic examination (pretest) consisted of 20 questions, each of which had four possible responses, of which only one was correct. The final examination (posttest), meanwhile, consisted of 10 questions, each of which had four possible responses, of which only one was correct.

The number of questions in the exams was different because, in the diagnostic test (pretest), we evaluated whether the students had the base required to understand the new knowledge concerning BA, that is, the students' knowledge with regard to the Theory of Sets [78], and we, therefore, evaluated the following: The concept of set, subset, union, intersection, symmetric difference, complement, idempotence, power set, de Morgan's law, associative law, distributive law, and Venn diagrams. This was done through the use of theoretical questions and practical exercises. The final exam (posttest), meanwhile, consisted of 10 questions containing problems that presented the initial information that the students should use in the form of a Boolean expression, K-Map, truth table or obtained from a logical circuit to then perform complex operations by applying K-Maps, the Q-Mc method, or BA theorems, to find the simplified Boolean function. The final exam took longer, signifying that it contained fewer questions, thus allowing the students to take the exam in the time frame of a single class.

The pretest/posttest examinations were applied to both groups (CG and EG) and were graded by the same professor on a scale of 0 to 100 .

\section{3 | Procedure}

The experiment took place during the August-December semester of 2019, with 62 undergraduates in the DM class who were studying on the BA unit. The participants were enrolled on the CSE degree at the TecNM on the ITM campus, and were randomly divided into two groups, CG) and EG. With regard to the participants' characteristics, the CG was made up of 26 men and 5 women, whereas the EG comprised 24 men and 7 women.
Table 3 shows a summary of the teaching-learning activities carried out in 20 days, during which the motivational strategies in Table 2 were applied to help students develop the specific competencies $\mathrm{SC} 1, \mathrm{SC} 2, \mathrm{SC} 3$, SC4, and SC5. Both groups (CG and EG) did the same traditional didactic activities during the learning process; the differences, however, lay in the way in which the learning was reinforced, as the CG continued employing conventional strategies using a pencil and paper, whereas the EG used the MiniBool software.

The first activity, therefore, consisted of giving a diagnostic examination to both groups (Day 1). This was designed to help the professor identify specific strengths and weaknesses to provide each student with corrective assistance and overcome any deficiencies, and consequently, consolidate the foundations on which the scaffolding process for new learning would be based [3]. The diagnostic examination was specifically designed to evaluate concepts, postulates, and the theoretical laws of sets, as set theory is the basis of various areas of computing, such as databases, formal languages, mathematical logic, and, of course, BA.

The students from both groups were, therefore, asked to read information related to BA as homework, to familiarize themselves with the material (Day 1). The information that was sent to each of the students by email was written and reviewed by the professor beforehand. This was done with the intention of saving the students the trouble of having to look for the information and having problems recognizing what would be useful and what would not [61].

From Day 2 to 15, the professor provided the same detailed explanation of the topics in the BA unit to both groups by means of classes in the classroom. In these classes, the students did exercises to practice and reinforce the learning, but this activity took place in a different manner for each group, as the CG students did the exercises using a pencil and paper, whereas the EG students resolved the same problems using MiniBool (Figure 4).

Keeping in mind that the time that could be dedicated to doing exercises in the classroom was limited, on days 16 and 17 , the students were given a list of exercises concerning the simplification of Boolean expressions to do outside the classroom. The CG students, therefore, carried out this task with a pencil and paper and then gave their responses to their professor for evaluation. The EG students, however, resolved the problems given to them by the professor, those that they had invented themselves, and/or those randomly generated by MiniBool, and it was the educational software that determined whether or not the solutions to the problems were correct. The professor supervised this activity for the EG 
T A B LE 3 The teaching-learning activities of the control and experimental groups (CG and EG)

\begin{tabular}{|c|c|}
\hline Day & Learning activity \\
\hline 1 & Reading of document containing general BA concepts (CG and EG) \\
\hline 2 & Lecture on introduction to BA (CG and EG) \\
\hline 3 & Lecture on the properties of the Boolean expressions (CG and EG) \\
\hline $4-6$ & $\begin{array}{l}\text { Resolution of exercises related to the simplification of Boolean functions by applying BA theorems, using a pencil and paper } \\
\text { (CG) or MiniBool (EG) }\end{array}$ \\
\hline $7-9$ & Lecture on simplification of Boolean functions by applying K-Maps (CG and EG) \\
\hline $7-9$ & $\begin{array}{l}\text { Resolution of exercises related to the simplification of Boolean functions by applying K-Maps, using a pencil and paper (CG) } \\
\text { or MiniBool (EG) }\end{array}$ \\
\hline 12 & Lecture on obtaining Boolean expressions from logic circuits (CG and EG) \\
\hline $13-15$ & Lecture on simplification of Boolean functions from logic circuits (CG and EG) \\
\hline $13-15$ & $\begin{array}{l}\text { Resolution of exercises related to the obtaining and simplification of Boolean expression from logical circuits, using a pencil } \\
\text { and paper (CG) or MiniBool (EG) }\end{array}$ \\
\hline $16-17$ & Resolution of exercises to reinforce the learning related to the BA unit, using a pencil and paper (CG) or MiniBool (EG) \\
\hline 18 & General review (CG and EG) \\
\hline 19 & Final exam (posttest; CG and EG) \\
\hline
\end{tabular}

students at a distance as the system registers the problems with the specific characteristics (number of variables, whether they were user-defined or softwaregenerated, etc.) that each student resolves.

The professor then gave a class to carry out a general review of the BA unit for both groups (Day 18), signifying that the students from both groups were able to ask questions regarding any doubts that they had about the educational content before the final exam. The students in both groups ( $\mathrm{CG}$ and $\mathrm{EG}$ ) were consequently given the same written examination (Day 19), which contained Boolean function simplification problems based on truth tables, K-Maps, or mathematical expressions denoted as an $\mathrm{SOP}$, a POS, or in a nonstandard form, such as $\mathrm{F}=\left(\mathrm{A}+\mathrm{B}^{\prime}\right.$ $\left.\mathrm{C}\left(\mathrm{CA}+\mathrm{BC}^{\prime}\right)^{\prime}+\mathrm{A}^{\prime} \mathrm{B}\right)^{\prime}\left(\mathrm{B}^{\prime} \mathrm{C}+\mathrm{A}^{\prime}\right)$. Both groups took the examination under the same conditions: In the same place, at the same time, and with the same duration, and all the examinations were graded by the same professor.
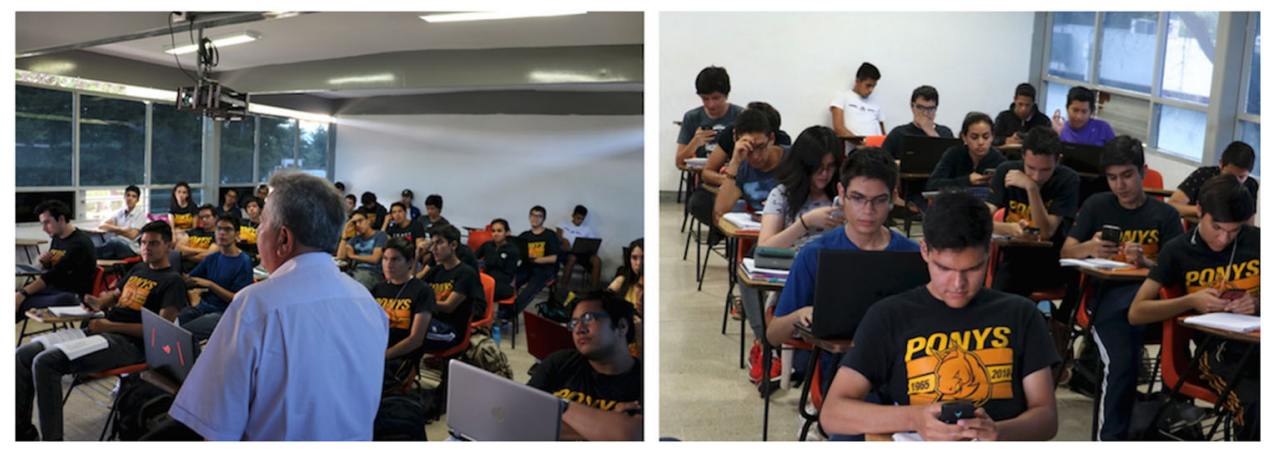

F I G URE 4 Students attending classes and using MiniBool on their mobile devices and personal computers 
TABLE 4 Descriptive statistics and $t$ test results (pretest)

\begin{tabular}{llllllll} 
Group & $\boldsymbol{n}$ & $\overline{\boldsymbol{x}}$ & $\begin{array}{l}\text { Standard } \\
\text { deviation }\end{array}$ & $\begin{array}{l}\text { Standard } \\
\text { Error }\end{array}$ & $\boldsymbol{t}$ & $\boldsymbol{d} \boldsymbol{f}$ & $\boldsymbol{p}$ \\
Control & 31 & 55.32 & 21.36 & 3.83 & 0.151 & 60 & .881 \\
\hline Experimental & 31 & 54.52 & 20.75 & 3.72 & & & \\
\hline
\end{tabular}

Lastly, the students in both groups were asked to respond to a questionnaire to discover their levels of motivation (Day 20). We designed this questionnaire (Appendix A) based on the Course Interest Survey (CIS) [40] to determine how motivated the students were according to the four ARCS factors. Thus, the questionnaire comprises 34 questions: Eight items for the Attention component, nine for the Relevance, eight for the Confidence, and nine for the Satisfaction. Each question has to be evaluated from 1 to 5 on a Likert scale, on which 1 corresponds with "Not true" and 5 corresponds with "Very true." Both groups responded to this questionnaire under the same conditions (same place, time, duration, professor, and scale of evaluation).

\section{7 | RESULTS}

\section{1 | Data analysis of the evaluation of learning}

The results of the diagnostic examination (pretest) and the final examination (posttest) were formally evaluated by means of a hypothesis test with an error of 5\% to determine the difference between the CG and EG's prior knowledge and that subsequently attained. The following hypotheses were, therefore, considered for the pretest:

$\mathrm{H}_{0}$ : There is no significant difference between the means of the CG's prior knowledge scores and those of the EG.

$\mathrm{H}_{1}$ : There is a significant difference between the means of the CG's prior knowledge scores and those of the EG.

Table 4 shows the basic statistics of both groups (CG and EG) that were obtained in the pretest, along with the results of the hypothesis test for the pretest, for which the assumptions of normality (CG, $W=0.958, p=.271$; EG, $W=0.977, p=.732)$ and homoscedasticity $(F=.0003$, $p=.954$ ) were fulfilled. It is, therefore, possible to observe that there is no significant difference between the means of the CG's prior knowledge scores and those of the EG, as there is a value of $p=.881>.05$, thus implying that neither the CG nor the EG students had advantages as regards their prior knowledge.

We also carried out a hypothesis test to discover whether there was a significant difference between the knowledge subsequently attained by the CG and EG students. The following hypotheses were, therefore, considered:

$\mathrm{H}_{0}$ : There is no significant difference between the means of the knwoledge scores attained by the CG and those of the EG.

$\mathrm{H}_{1}$ :There is a significant difference between the means of the knowledge scores attained by the CG and those of the EG.

Table 5 shows the basic statistics obtained in the CG's and the EG's posttest. It also shows the results of the hypothesis test in the posttest, for which the assumptions of normality (CG, $W=0.929, p=.573$; EG, $W=0.925$, $p=.771)$ and homogeneity of variances $(F=3.319$; $p=.073$ ) were fulfilled. It is similarly possible to observe that there is a significant difference between the means of the CG and those of the EG as the value of $p=.027<.05$. It is thus possible to conclude that those students who learned about Boolean function simplification with the support of MiniBool $(M=80)$ did indeed attain more knowledge (Figure 5). The statistical results shown in this paper were obtained using the IBM SPSS Statistics $($ C software.

\section{2 | Data analysis of the evaluation of motivation}

The internal consistency of the questionnaire for the evaluation of the motivation was verified by calculating the Cronbach's $\alpha$. This coefficient, which was developed by Lee Cronbach, is an indicator that allows the

TABLE 5 Descriptive statistics and $t$ test results (posttest)

\begin{tabular}{llllllll} 
Group & $\boldsymbol{n}$ & $\overline{\boldsymbol{x}}$ & $\begin{array}{l}\text { Standard } \\
\text { deviation }\end{array}$ & $\begin{array}{l}\text { Standard } \\
\text { Error }\end{array}$ & $\boldsymbol{t}$ & $\boldsymbol{d} \boldsymbol{p}$ & $\boldsymbol{p}$ value \\
Control & 31 & 70.00 & 20.49 & 3.68 & -2.261 & 60 & .027 \\
Experimental & 31 & 80.00 & 13.66 & 2.45 & & & \\
\hline
\end{tabular}




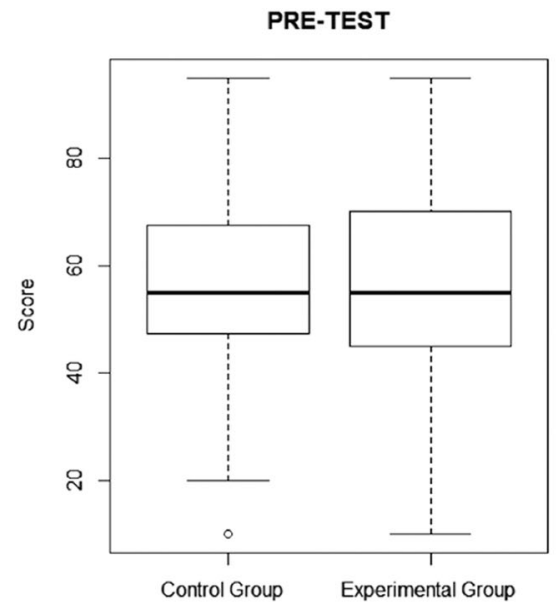

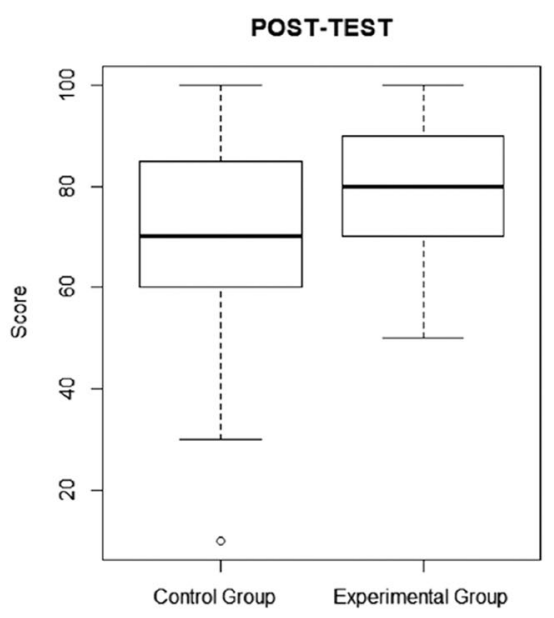

FIGURE 5 Comparative box plot of the students' academic performance
T A B LE 6 Internal consistency estimates (questionnaire for the evaluation of motivation)

\begin{tabular}{lll} 
& \multicolumn{2}{c}{ Cronbach's $\boldsymbol{\alpha}$} \\
\cline { 2 - 3 } Factor & Control group & Experimental group \\
\hline Attention & .89 & .84 \\
\hline Relevance & .81 & .87 \\
\hline Confidence & .93 & .93 \\
\hline Satisfaction & .94 & .80 \\
\hline Total factors & .89 & .86 \\
\hline
\end{tabular}

reliability of an evaluation instrument to be measured [13]. The results of Cronbach's $\alpha$ for the ARCS factors of the two groups (CG and EG) are contained in Table 6. All of them are greater than .70 , which indicates that there is sufficient reliability in the questionnaire applied [76].

The results of the questionnaire employed to evaluate motivation, which was applied to both groups in the posttest, were formally evaluated by means of hypothesis tests with a confidence level of $95 \%$ to determine whether there was a significant difference between each motivation factor. Table 7 shows the basic statistics and the results of the $t$ tests that were conducted for each of the
ARCS factors, for which the assumptions of the normality and the homoscedasticity were previously fulfilled in all cases. These tests yielded statistically significant differences between both groups for Attention, $t(60)=-4.709$, $p=.000015$; Relevance, $t(60)=-3.470, p=.000964$, and Satisfaction, $t(60)=-4.561, p=.000025$ (Figure 6).

Despite what is stated above, it is possible to observe that there is a significant difference between the means in the Total factors of the CG and those of the EG, as the value of $p=.000194<.05$, thus reflecting that the students in the EG were, in general, more motivated with the B-Learning teaching method, which combines the traditional learning method with the use of MiniBool software as a reinforcement, in comparison to the students in the CG, who learned by attending classes and reinforced their knowledge doing exercises with a pencil and paper.

\section{8 | THREATS TO VALIDITY}

When carrying out an experiment, it is necessary to evaluate whether its results are valid [87]. It is for this reason that Cook and Campbell [11] defined four types of threats that may compromise the validity of an experiment: Internal, external, construct, and conclusion.

\begin{tabular}{|c|c|c|c|c|c|c|c|}
\hline \multirow[b]{2}{*}{ Factor } & \multicolumn{2}{|c|}{ Control group } & \multicolumn{2}{|c|}{ Experimental group } & \multirow[b]{2}{*}{$t$} & \multirow[b]{2}{*}{$d f$} & \multirow[b]{2}{*}{$p$ value } \\
\hline & $\overline{\boldsymbol{x}}$ & $\begin{array}{l}\text { Standard } \\
\text { deviation }\end{array}$ & $\overline{\boldsymbol{x}}$ & $\begin{array}{l}\text { Standard } \\
\text { deviation }\end{array}$ & & & \\
\hline Attention & 3.34 & 0.41 & 3.85 & 0.44 & -4.709 & 60 & .000015 \\
\hline Relevance & 3.25 & 0.32 & 3.56 & 0.38 & -3.470 & 60 & .000964 \\
\hline Confidence & 4.02 & 0.67 & 4.23 & 0.53 & -1.391 & 60 & .169174 \\
\hline Satisfaction & 3.99 & 0.66 & 4.57 & 0.29 & -4.561 & 60 & .000025 \\
\hline Total factors & 3.65 & 0.64 & 4.05 & 0.57 & -3.971 & 60 & .000194 \\
\hline
\end{tabular}

TABLE 7 Descriptive statistics and $t$ test results (motivation factors) 

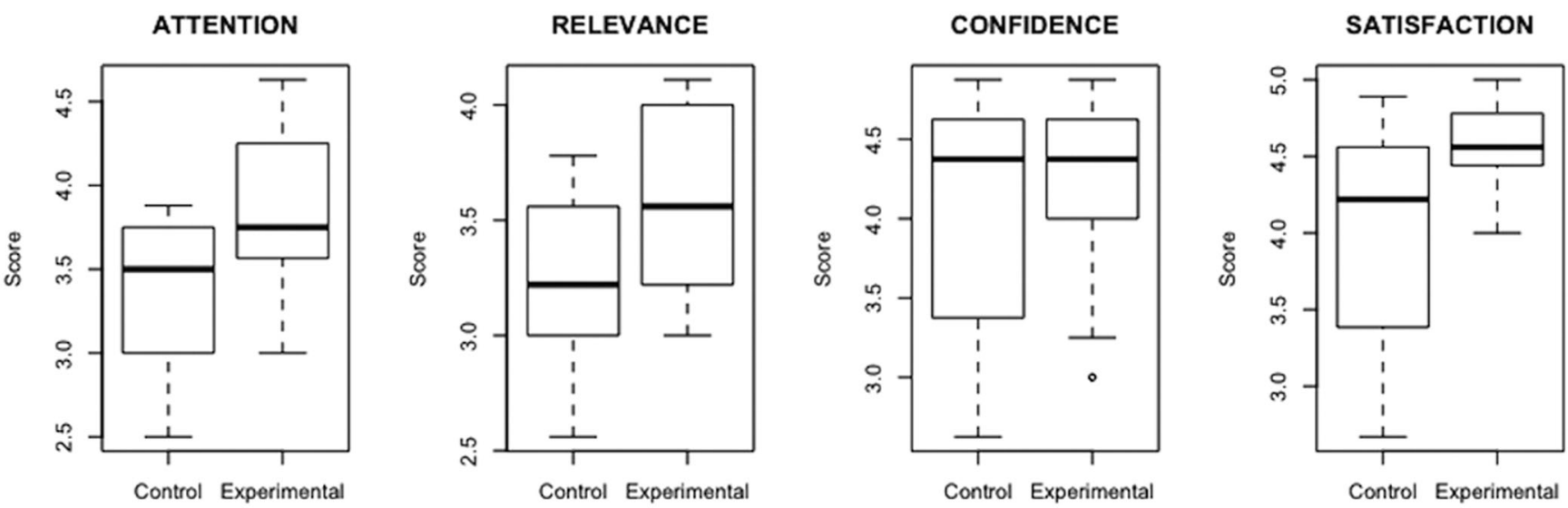

FIG URE 6 Comparative box plot of the motivation factors

With regard to the internal validity of the experiment, we avoided subjecting the participants to a selection effect by randomly dividing them into the two groups (CG and EG), in addition to which they were given a diagnostic examination that allowed us to corroborate that neither of the groups had a significant advantage as regards their prior knowledge, thus ensuring statistical equivalence. Moreover, to avoid instability in the experimental environment, the students in both groups carried out the experiment in the same conditions and facilities and had the same professor, the same reading material on BA, and the same face-to-face classes. Similarly, to minimize a possible instrumentation effect, the pretest and posttest examinations were given to both groups by the same professor, in the same place, and at the same time, and were graded by the same professor on the same scale. As none of the participants dropped out of the experiment, it is possible to state that there was no mortality effect.

The threats to the internal validity of the experiment were not, however, completely nonexistent, as the participants in both groups (CG and EG) study at the same educational institution and diffusion of treatments could, therefore, have occurred. It was similarly not possible, in the case of the EG, to exclude the presence of a maturity effect, as the students in that group could have carried out more simplifications of Boolean expressions owing to the fact that they had solved additional problems (the random exercises generated by MiniBool), which may have increased their cognitive structure.

With regard to external validity, the fact that the experiment took place in an academic context and was not replicated reduces the possibility of the results being generalized.

In the case of construct validity, a pilot test was carried out before the experiment took place, and this enabled us to make adjustments to the activities in the teaching-learning process and to the evaluation instruments. The pretest and posttest measurement instruments, therefore, had a similar structure but were not the same to avoid the learning effect.

With regard to the threats to the conclusion validity, the normality and homoscedasticity tests were carried out before the $t$ test in the pretest and posttest, to avoid any effects on the reliability of the statistical analysis. Moreover, a confidence level of 95\% was considered when performing all the statistical tests.

Furthermore, with respect to the evaluation of motivation, the principles of scientific research in education of [53] were taken into account, which indicates that before selecting an evaluation tool in a study, two aspects must be considered: The validity and the reliability of the instrument. Validity can be understood as the extent to which an instrument measures what it claims to measure, whereas reliability indicates the extent to which an instrument can be expected to provide the same result if measurements are repeated. In this respect, there is evidence that the CIS motivation-evaluation instrument is valid, as it has been used in several studies in various contexts [54]. Similarly, the psychometric properties of the CIS instrument indicate that it is a reliable tool with which to measure motivation, given that the Cronbach's $\alpha$ coefficient reported in many studies exceeds .70 [54], which is considered a sufficient value to ensure its reliability [76].

\section{9 | FINDINGS AND DISCUSSION}

\section{1 | Students' academic performance}

To discover whether there were improvements in the students' academic achievement when learning to simplify Boolean functions in a B-Learning setting with the 
MiniBool software, in comparison to the face-to-face teaching-learning method, which was the first concern that led this study (RQ1), a formal experiment was carried out. Its results show that the EG students obtained better grades when supporting their study with the technology-based educational tool than the CG students who did not.

The final exam (posttest) comprised 10 questions in which, in Problems 1 and 2, the students were required to obtain the simplified Boolean function from a truth table; in Problems 3 and 4, they were required to obtain the simplified Boolean function from a K-Map; in Problems 5 and 6, they were required to obtain the simplified Boolean function from a Boolean expression with nested parentheses, in which some of those parentheses were affected by complements; in Problem 7, they were required to obtain the simplified Boolean function from an expression in an SOP; in Problem 8, they were required to obtain the simplified Boolean function from an expression in a POS, and in Exercises 9 and 10, given a logic circuit connected with basic logic gates (and, or, not, $\mathrm{x}$ or) and combined gates (nand, nor, x-nor), they were required to obtain the Boolean expression of the circuit and then simplify it. The CG and EG students answered each of the questions in the final exam, which is shown in Table 8.

The results of the analysis of the answers to the questions in the final exam show that, for both groups, the greatest difficulty as regards learning concerned the correct application of de Morgan's law, because in

TA B LE 8 Number and percentage of students in both groups who correctly answered each question in the final exam

\begin{tabular}{|c|c|c|c|c|}
\hline \multirow[b]{2}{*}{ Question no. } & \multicolumn{2}{|c|}{ Control group } & \multicolumn{2}{|c|}{ Experimental group } \\
\hline & $\begin{array}{l}\text { No. } \\
\text { Stud. AC }\end{array}$ & $\begin{array}{l}\% \\
\text { Stud. } \\
\text { AC }\end{array}$ & $\begin{array}{l}\text { No. } \\
\text { Stud. AC }\end{array}$ & $\begin{array}{l}\% \\
\text { Stud. AC }\end{array}$ \\
\hline 1 & 27 & 87.10 & 27 & 87.10 \\
\hline 2 & 22 & 70.97 & 25 & 80.65 \\
\hline 3 & 24 & 77.42 & 27 & 87.10 \\
\hline 4 & 22 & 70.97 & 25 & 80.65 \\
\hline 5 & 21 & 67.74 & 23 & 74.19 \\
\hline 6 & 19 & 61.29 & 23 & 74.19 \\
\hline 7 & 21 & 67.74 & 27 & 87.10 \\
\hline 8 & 22 & 70.97 & 25 & 80.65 \\
\hline 9 & 19 & 61.29 & 22 & 70.97 \\
\hline 10 & 20 & 64.52 & 24 & 77.42 \\
\hline
\end{tabular}

Abbreviations: No. Stud. AC, number of students who answered correctly; \% Stud. AC, percentage of students who answered correctly.
Problems 5 and 6, this law should be applied to eliminate parentheses and carry out the corresponding reduction in information by applying other BA laws. This theory was corroborated in Questions 9 and 10, in which, from a logical circuit, the students had to obtain a Boolean function whose expression contained information in parentheses affected by a complement, resulting from the not, nand, nor, x-nor gates. To simplify this Boolean function they, therefore, had to apply de Morgan's law again. It is consequently possible to state that the main problem as regards learning BA lies in the correct application of the BA laws, of which de Morgan's law stands out. This is consistent with what is stated in Reference [24].

The experiment was carried out at the TecNM on the ITM campus. The TecNM is made up of 248 campuses, in which a total of 608,283 students are enrolled, thus making it the higher education institution with the largest population of engineering students in Mexico [77]. Of this total population, 58,426 TecNM students study the CSE degree. In the first semester of their studies, they take the DM course based on the same content described in Section 3.1. This subject is also taught in the study programs of other degrees at TecNM, such as the Information and Communication Technology Bachelor's degree. The BA unit is additionally covered in other subjects, such as Computer Architecture, Hydraulic and Pneumatic Design, and Digital Design, which corresponds to the Electrical, Mechanical, and Electronic Engineering degrees, respectively. The findings of this study could, therefore, improve the academic performance of a large student population.

\section{2 | Students' level of motivation}

Another of the questions that arose when we proposed this study was that of discovering whether the students' level of motivation could be improved when learning to simplify Boolean functions in a B-Learning setting using the MiniBool software, in comparison to a traditional learning method (RQ2). The results of the statistical analysis of this study show that for three of four factors evaluated as regards the students' motivation (A, R, and $\mathrm{S}$ ), the students in the EG were significantly more motivated during the teaching-learning process when compared to those in the CG. This allows us to state that it was, according to the pedagogical principles of socioconstructivism and humanism, possible to build an effective instructional system in which active, self-regulated, and problem-solvingoriented learning with a playful and practical treatment allows the learning of contents and skills. The implementation of an approach focused on the person who 
learns, as regards their experiences, previous capacities, and interests is, therefore, reflected in the results of the various dimensions explored in the motivation to learn:The achievement of greater attention, relevance, and satisfaction.

One of the learner-centered educational principles that was crucial as regards obtaining the results reported in this study was the feedback provided by MiniBool, as it allowed the students to know how well they were progressing and performing in an updated and constant manner [79]. The gamification element included in MiniBool similarly promoted intrinsic motivation and autotelic behavior (persistence and satisfaction in the activity owing to interest in itself) [48].

We consider that innovation is present in this experience, which deals with the configuration of new learning scenarios in the face of the emergence of new teaching-learning environments or ecologies [10], in which it is essential to create flexible and playful strategies. This is done through the mediation of digital technologies, which generate sense and meaning, as these types of experiences, not only provide information, but also enable the development of generic competencies, such as those related to strategic thinking, decision-making, and the capacity to solve complex problems [68].

\section{3 | Using MiniBool in other pedagogical models and courses}

Given the positive results obtained when using the MiniBool educational software tool in a B-Learning setting, the question arises: Could MiniBool be used with other pedagogical models? The pedagogical model used in this study, B-Learning, was selected after considering the content of the curriculum of the DM course and the learning outcomes of the BA unit, along with the positive evidence of use reported in some related works $[8,30]$. However, other pedagogical models have also proven to be effective in computing and engineering education, such as flipped classroom and project-based learning.

Nwokeji and Holmes [58] define the flipped classroom model as a pedagogical paradigm that reverses the order and the location in which learning activities occur in the traditional model, that is, knowledge is imparted at home, whereas students spend class time participating in homework. This pedagogical model could, therefore, be implemented by designing some forms of multimedia content with which to teach the simplification of Boolean functions, such as videos or podcasts, to deliver the traditional lecture content outside the classroom and then using MiniBool to solve exercises in the classroom.
Project-based learning, which is a pedagogical model in which students learn by investigating and solving realworld problems in an open-ended, time-limited context, as defined by Habók and Nagy in Reference [19], could, meanwhile, also be employed with MiniBool. This could be done by applying the cross-course project-based learning approach of Nwokeji and Frezza [57], by combining two courses in the first semester of the CSE degree, for example, fundamentals of programming and $\mathrm{DM}$, thus enabling the students to develop algorithms that involve the use of logical operators and the simplification of simple and complex Boolean expressions (those that appear in logical statements of conditional instructions and logical-mathematical loops).

Another question also emerges: Could MiniBool be used on courses other than DM? The BA unit, which is part of the DM course, is a subject that is part of the study plan of all the degrees in the area of computing, as it is an essential course as regards learning databases, computer architecture, systems digital or networks, among others. But BA is also closely related to the areas of Electrical and Electronic Engineering, where it was first used [70] to allow the development of digital circuits based on logic gates. BA is additionally used in the area of Mechanics, in hydraulic and pneumatic circuits. Everything that has an automatic operation, therefore, requires BA, signifying that MiniBool could be useful as regards teaching this topic on other courses. This suggests that MiniBool could, in theory, be used with other pedagogical models and on other courses, but does not allow us to predict results because, as stated in [58], the results may vary owing to the natural changes of the experimental objects: Different instructional models, different courses, different teachers, different students, different learning styles, and so forth.

\section{0 | CONCLUSION AND FUTURE WORK}

The results of this study provide an initial indicator suggesting that the use of the web-based software denominated as MiniBool, may be beneficial as regards reinforcing the learning of the simplification of Boolean functions in a B-Learning context. These results coincide with those presented in $[83,88]$, which provides evidence that the use of a mixed approach in the teaching-learning process (face-to-face combined with technology) is more effective than simply employing the traditional method.

From the practical point of view, MiniBool provides the opportunity to learn any time and anywhere, with tolerance to error and a sense of achievement by means of gamification. This occurs when the student does an exercise in the system and obtains points that depend on 
the complexity of the problem solved. These points are, in turn, reflected in a ranking that compares them with those obtained by the other students. MiniBool also allows the professor to monitor the students' participation, as the system registers the date and time when a student has done a particular exercise, the characteristics of that exercise, and whether or not it was done correctly. The tool additionally provides statistical graphs and allows the students and the professor to communicate by means of messages.

MiniBool has been positively tested as part of a formal experiment by undergraduates attending the subject of $\mathrm{DM}$ at the TecNM, on the ITM campus while studying the BA unit. The statistical results obtained show that the students who used MiniBool to reinforce their learning obtained better grades in the final examination than those who did exercises in a traditional manner using a pencil and paper. The results of the questionnaire employed to evaluate the students' motivation also reflected the fact that MiniBool makes it possible to obtain higher levels of attention, relevance, and satisfaction than the use of the traditional reinforcement method.

As stated throughout this study, MiniBool allows the simplification of user-defined Boolean functions of $n$ variables, which can be introduced by means of truth tables, K-Maps, or mathematical expressions. It similarly allows the simplification of software-generated Boolean functions. In the future, we, therefore, intend to include the graphical representation of basic and combined logical digital gates in MiniBool. As future work, we are also considering repeating the experiment with students from other institutions, in addition to exploring the use of MiniBool with other pedagogical models, such as the flipped classroom and project-based learning.

\section{ACKNOWLEDGMENTS}

The authors would like to thank Michel Olvera, Alan Cruz, and Jorge Arreygue for participating in the development of MiniBool. Moreover, they are very grateful to José A. Jiménez Murillo for allowing them to use his facilities to carry out the experiment with his DM groups. Special thanks also go to Octavio Ortiz, Paola Jiménez, and Guillermina Eslava for reviewing the statistical analysis, and to all the students who participated in the experiment. The authors would like to acknowledge the Consejo Nacional de Ciencia y Tecnología (CONACYT) for its financial support.

\section{DATA AVAILABILITY STATEMENT}

Data available on request from the authors. The data that support the findings of this study are available from the corresponding author upon reasonable request.

\section{ORCID}

Eréndira M. Jiménez-Hernández (1) http://orcid.org/00000002-5333-1992

Hanna Oktaba (iD http://orcid.org/0000-0003-2852-4490

Frida Díaz-Barriga (1) http://orcid.org/0000-0001-

8720-1857

Mario Piattini (D) http://orcid.org/0000-0002-7212-8279

\section{REFERENCES}

1. P. Agrawal, V. D. Agrawal, and N. N. Biswas, Multiple output minimization, Proc. 22nd ACM/IEEE Des. Automat. Conf., Las Vegas, NV, 1985, pp. 674-680. https://doi.org/10.1109/DAC. 1985.1586015

2. C. Avilés-Cruz and J. Villegas-Cortez, A smartphone-based augmented reality system for university students for learning digital electronics, Comput. Appl. Eng. Educ. 27 (2019), no. 3, 615-630. https://doi.org/10.1002/cae.22102

3. J. R. Betts, Y. Hahnb, and A. C. Zau, Can testing improve student learning? An evaluation of the mathematics diagnostic testing Project, J. Urban Econ. 100 (2017), 54-64. https://doi. org/10.1016/j.jue.2017.04.003

4. C. Bo et al., The Boolean Algebra Logic: The soundness and completeness theorem, Proc. 2017 13th Internat. Conf. Semant. Knowl. Grids (SKG), Beijing, 2017, pp. 15-18. https://doi.org/ 10.1109/SKG.2017.00011

5. R. Boelens et al., The design of blended learning in response to student diversity in higher education: Instructors' views and use of differentiated instruction in blended learning, Comput. Educ. 120 (2018), 197-212. https://doi.org/10.1016/j.compedu.2018. 02.009

6. Boolean Expression Calculator, dCode, 2009, available at https://www.dcode.fr/boolean-expressions-calculator

7. M. Callaghan et al., Mapping learning and game mechanics for serious games analysis in engineering education, IEEE Trans. Emerg. Top. Com. 5 (2017), no. 1, 77-83. https://doi.org/10. 1109/TETC.2015.2504241

8. Y. S. Choi, Effectiveness of game-based learning to minimize Boolean functions, Multimed. Tools Appl. 74 (2015), no. 17, 7131-7146. https://doi.org/10.1007/s11042-014-1956-8

9. L. Cohen, L. Manion, and K. Morrison, Research Methods in Education, Routledge, London, UK, 2017.

10. C. Coll, El currículo escolar en el marco de la nueva ecología del aprendizaje, Aula 219 (2013), 31-36.

11. T. D. Cook and D. T. Campbell, Quasi-experimentation: Design and analysis issues for field settings, Houghton Mifflin, Boston, MA, 1979.

12. T. D. Cook and D. T. Campbell, The causal assumptions of quasi-experimental practice, Synthese 68 (1986), no. 1, 141-180. https://doi.org/10.1007/BF00413970

13. L. J. Cronbach, Coefficient alpha and the internal structure of tests, Psychometrika 16 (1951), 297-334. https://doi.org/10. 1007/BF02310555

14. L. de-Marcos, E. Garcia-Lopez, and A. Garcia-Cabot, On the effectiveness of game-like and social approaches in learning: Comparing educational gaming, gamification \& social networking, Comput. Educ. 95 (2016), 99-113. https://doi.org/10. 1016/j.compedu.2015.12.008 
15. O. Deperlioglu and U. Kose, The effectiveness and experiences of blended learning approaches to computer programming education, Comput. Appl. Eng. Educ. 21 (2013), no. 2, 328-342. https://doi.org/10.1002/cae.20476

16. A. Domínguez et al., Gamifying learning experiences: Practical implications and outcomes, Comput. Educ. 63 (2013), 380-392. https://doi.org/10.1016/j.compedu.2012.12.020

17. D. Furió et al., Evaluation of learning outcomes using an educational iPhone game vs. traditional game, Comput. Educ. 64 (2013), 1-23. https://doi.org/10.1016/j.compedu.2012.12.001

18. A. Garcia-Cabot et al., Measuring the effects on learning performance and engagement with a gamified social platform in an MSc program, Comput. Appl. Eng. Educ. 28 (2020), 207-223. https://doi.org/10.1002/cae.22186

19. A. Habók and J. J. Nagy, In-service teachers' perceptions of project-based learning, SpringerPlus 5 (2016), no. 83, 1-14. https://doi.org/10.1186/s40064-016-1725-4

20. C. Hacker and R. Sitte, Interactive teaching of elementary digital logic design with WinLogiLab, IEEE Trans. Educ. 47 (2004), no. 2, 196-203. https://doi.org/10.1109/TE.2004.824843

21. J. Hamari, Perspectives from behavioral economics to analyzing game design patterns: Loss aversion in social games, Paper presented at the CHI2011 Social Games Workshop, Vancouver, British Columbia, Canada, 2011.

22. J Hamari, J Koivisto, and H. Sarsa, Does gamification work?-A literature review of empirical studies on gamification, Proc. 2014 47th Hawaii Internat. Conf. Sys. Sci. Waikoloa, HI, 2014, pp. 3025-3034. https://doi.org/10.1109/HICSS.2014.377

23. L. Harnab et al., Realizing secret sharing with general access structure, Inform. Sci. 367-368 (2016), 209-220. https://doi.org/ 10.1016/j.ins.2016.06.006

24. G. L. Herman and J. Handzik, A preliminary pedagogical comparison study using the digital logic concept inventory, Proc. 2010 IEEE Front. Educ. Conf. (FIE), Washington, DC, 2010, pp. F1G-1-F1G-6. https://doi.org/10.1109/FIE.2010.5673591

25. K Huotari and J. Hamari, Defining gamification: A service marketing perspective, Proc. 16th Int. Acad. MindTrek Conf. (MindTrek '12), Association for Computing Machinery, New York, NY, 2012, pp. 17-22. https://doi.org/10.1145/2393132.2393137

26. M. B. Ibáñez, A. Di-Serio, and C. Delgado-Kloos, Gamification for engaging computer science students in learning activities: A case study, IEEE Trans. Learn. Technol. 7 (2014), no. 3, 291-301. https://doi.org/10.1109/TLT.2014.2329293

27. Y. Jia et al., Personality-targeted gamification: A survey study on personality traits and motivational affordances, Proc. $2016 \mathrm{CHI}$ Conf. Human Factors Comput. Sys (CHI '16), Association for Computing Machinery, New York, NY, 2016, pp. 2001-2013. https://doi.org/10.1145/2858036.2858515

28. E. M. Jiménez-Hernández et al., Methodology to construct educational video games in software engineering, Proc. 2016 4th Internat. Conf. Softw. Eng. Res. Innovat. (CONISOFT), Puebla, 2016, pp. 110-114. https://doi.org/10.1109/CONISOFT.2016.25

29. E. M. Jiménez-Hernández et al., Serious games when used to learn software processes: An Analysis from a Pedagogical Perspective, Proc. 2017 5th Internat. Conf. Softw. Eng. Res. Innovation (CONISOFT), Mérida; 2017, pp. 194-203. https:// doi.org/10.1109/CONISOFT.2017.00031

30. J. A. Jiménez-Murillo et al., B-Learning in the teaching-learning of Boolean function simplification, Proc. 2018 6th Internat.
Conf. Softw. Eng. Res. Innovat. (CONISOFT), San Luis Potosí, Mexico, 2018, pp. 21-26. https://doi.org/10.1109/CONISOFT. 2018.8645934

31. J. Jo, H. Jun, and H. Lim, A comparative study on gamification of the flipped classroom in engineering education to enhance the effects of learning, Comput. Appl. Eng. Educ. 26 (2018), no. 5, 1626-1640. https://doi.org/10.1002/cae.21992

32. M. Jurgelaitis et al., Implementing gamification in a universitylevel UML modeling course: A case study, Comput. Appl. Eng. Educ. 27 (2018), no. 2, 332-343. https://doi.org/10.1002/cae. 22077

33. M. Jurgelaitis et al., Implementing gamification in a universitylevel UML modeling course: A case study, Comput. Appl. Eng. Educ. (2018), 1-12. https://doi.org/10.1002/cae.22077

34. K. Y. Kabalan et al., Computer tool for minimizing logic functions, Comput. Appl. Eng. Educ. 3 (1995), no. 1, 55-64. https:// doi.org/10.1002/cae.6180030108

35. M. Karnaugh, The map method for synthesis of combinational logic circuits, Trans. Am. Inst. Elec. Eng. 72 (1953), no. 5, 593-599. https://doi.org/10.1109/TCE.1953.6371932

36. Karnaugh Map Analyzer (Windows) 1.0, Sof112. 2012, available at https://karnaugh-map-analyzer-windows.soft112.com

37. Karnaugh Minimizer. ShurikSoft. 2002, available at http:// karnaugh.shuriksoft.com

38. R. Kaur and Pooja, A non-OCR approach for math CAPTCHA design based on Boolean algebra using digital gates to enhance web security, Proc. 2016 Internat. Conf. Wirel. Commun., Signal. Process. Netw. (WiSPNET), Chennai, 2016, pp. 862-866. https://doi.org/10.1109/WiSPNET.2016.7566254

39. J. M. Keller, Development and use of the ARCS model of motivational design, J Instruct Develop. 10 (1987), no. 3, 2-10.

40. J. Keller, Development of two measures of learner motivation, Florida State University, Tallahassee, FL, 2006.

41. J. M. Keller, Motivational design for learning and performance: The ARCS Model Approach, Springer, New York, NY, 2010.

42. J. M. Keller and K. Suzuki, Learner motivation and e-learning design: a multinationally validated process, J. Educ. Media 29 (2004), no. 3, 229-239.

43. F. M. Kifetew et al., Gamifying collaborative prioritization: Does pontification work? Proc. 2017 IEEE 25th Internat. Requirements Eng. Conf. (RE), Lisbon, 2017, pp. 322-331. https://doi. org/10.1109/RE.2017.66

44. D. A. Kolb, Experiential learning: Experience as the source of learning and development, Prentice-Hall, Englewood Cliffs, NJ, 1984.

45. N. Luo, M. Zhang, and D. Qi, Effects of different interactions on students' sense of community in e-learning environment, Comput. Educ. 115 (2017), 153-160. https://doi.org/10.1016/j. compedu.2017.08.006

46. P.-O. Löwdin, On Boolean algebra and its importance for the computer sciences, Int. J. Quant. Chem. 42 (1992), no. 4, 719-726. https://doi.org/10.1002/qua.560420412

47. A. Majumder et al., Investigation on Quine-McCluskey method: A decimal manipulation based novel approach for the minimization of Boolean function, Proc. 2015 Internat. Conf. Electron. Des., Comput. Netw. Automat. Verificat. (EDCAV), Shillong, 2015, pp. 18-22. https://doi.org/10.1109/EDCAV.2015.7060531

48. B. Marcano, Juegos serios y entrenamiento en la sociedad digital, Rev. Elect. Teor. Educ. Cult. Soc. Inform. 9 (2008), no. 3, 93-107. 
49. E. J. McCluskey Jr, Minimization of Boolean functions, Bell. Syst. Technol. J. 35 (1956), no. 6, 1417-1444. https://doi.org/10. 1002/j.1538-7305.1956.tb03835.x

50. R. R. McCrae and P. T. Costa, Reinterpreting the Myers-Briggs type indicator from the perspective of the Five-Factor Model of personality, J. Pers. 57 (1898), no. 1, 17-40.

51. M. D. Merrill et al., Reclaiming instructional design, Educ. Technol. 36 (1996), no. 5, 5-7.

52. MiniBool, 2019, available at http://minibool.com/

53. National Research Council Committee on Scientific Principles for Educational Research, Scientific Research in Education, National Academies Press, Washington DC, 2002.

54. T. Naveed and N. Mazhar, Validation of course interest survey tool in MBBS students of a private medical college of Pakistan, J. Islam. Int. Med. Coll. 12 (2017), no. 4, 201-207.

55. M. Nejati et al., Analysis of an asymmetric cryptosystem based on boolean matrices and permutations, Proc. 2015 Internat. Congr. Technol., Commun. Knowl. (ICTCK), Mashhad, 2015, pp. 306-311. https://doi.org/10.1109/ICTCK.2015.7582687

56. M. Nowostawski, S. McCallum, and D. Mishra, Gamifying research in software engineering, Comput. Appl. Eng. Educ. 26 (2018), no. 5, 1641-1652. https://doi.org/10.1109/ICTCK.2015. 7582687

57. J. C. Nwokeji and P. S. T. Frezza, Cross-course project-based learning in requirements engineering: An eight-year retrospective, Proc. 2017 IEEE Fronti. Educ. Conf. (FIE), Indianapolis, IN, 2017, pp. 1-9. https://doi.org/10.1109/FIE.2017.8190731

58. J. C. Nwokeji and T. S. Holmes, The impact of learning styles on student performance in flipped pedagogy, Proc. 2017 IEEE Front. Educ. Conf. (FIE), Indianapolis, IN, 2017, pp. 1-7. https://doi.org/10.1109/FIE.2017.8190522

59. M. Ortiz-Rojas, K. Chiluiza, and M. Valcke, Gamification through leaderboards: An empirical study in engineering education, Comput. Appl. Eng. Educ. 27 (2019), 777-788. https:// doi.org/10.1002/cae.12116

60. O. Ortíz-Ortíz, J. A. Jiménez-Murillo, and E. M. JiménezHernández $A$ web framework to improve computer programming learning, Proc. 2018 IEEE Internat. Aut. Meet. Power, Electron. Comput. (ROPEC), Ixtapa, Mexico, 2018, pp. 1-6. https://doi.org/10.1109/ROPEC.2018.8661409

61. N. Parsazadeha, R. Ali, and M. Rezaei, A framework for cooperative and interactive mobile learning to improve online information evaluation skills, Comput. Educ. 120 (2018), 75-89. https://doi.org/10.1016/j.compedu.2018.01.010

62. S. R. Petrick, A direct determination of the irredundant forms of a Boolean function from the set of prime implicants. AFCRC-TR-56-110, USAF Cambridge Res. Cen., Bedford, MA, 1956.

63. A. Picciano, C. Dziuban, and C. Graham, Blended learning: Research perspectives, 2, Routledge, Abingdon, UK, 2013.

64. J. Pinal et al., Experimental B-learning laboratory for an electrical machines undergraduate course, IEEE Lat Am T. 14 (2016), no. 2, 524-529. https://doi.org/10.1109/TLA.2016.7437188

65. W. V. Quine, A way to simplify truth functions, Am. Math. Month. 62 (1955), no. 9, 627-631. https://doi.org/10.1080/ 00029890.1955 .11988710

66. A. T. Rahem et al., New mathematical model to find the shortest path based on Boolean algebra operations for networks, Proc. 2016 IEEE 3rd Internat. Symp. Telecommun. Technol. (ISTT),
Kuala Lumpur, 2016, pp. 112-114. https://doi.org/10.1109/ ISTT.2016.7918095

67. T. S. Rathore and A. Jain, A systematic map method for realizing minimal logic functions of arbitrary number of variables, Proc. 2014 Internat. Conf. Circuits, Syst., Commun. Inform. Technol. Appl. (CSCITA), Mumbai, 2014, pp. 81-86. https://doi.org/10. 1109/CSCITA.2014.6839239

68. Ch. Reigeluth, ¿En qué consiste la teoría de diseño educativo y cómo se está transformando? Diseño de la instrucción. Teorías y modelos, Aula XXI/Santillana, Madrid, Spain, 2000.

69. D. J. Russomanno and R. D. Bonnell, A pedagogical approach to database design via Karnaugh Maps, IEEE Trans. Educ. 42 (1999), no. 4, 261-270. https://doi.org/10.1109/13.804530

70. T. Sasao and J. T. Butler, Worst and best irredundant sum-ofproduct expressions, IEEE Trans. Educ. 50 (2001), no. 9, 935-947. https://doi.org/10.1109/12.954508

71. E. Scheihing et al., Understanding the role of micro-blogging in B-learning activities: Kelluwen experiences in Chilean public schools, IEEE Trans. Learn. Technol. 11 (2018), no. 3, 280-293. https://doi.org/10.1109/TLT.2017.2714163

72. A. H. Scheinman, A method for simplifying Boolean functions, Bell. Syst. Technol. J. 41 (1962), no. 4, 1337-1346. https://doi. org/10.1002/j.1538-7305.1962.tb03280.x

73. Simple Solver, SimpleSolver Logic, available at https://www. simplesolverlogic.com/index.html

74. R. Smiderle et al., The impact of gamification on students' learning, engagement and behavior based on their personality traits, Smart Learn. Environ. 7 (2020), no. 3, 1-11. https://doi. org/10.1186/s40561-019-0098-x

75. M. Tabandeh, Application of Karnaugh map for easy generation of error-correcting codes, Sci. Iran 19 (2012), no. 3, 690-695. https://doi.org/10.1016/j.scient.2011.08.030

76. K. S. Taber, The use of Cronbach's alpha when developing and reporting research instruments in science education, Res. Sci. Educ. 48 (2018), 1273-1296. https://doi.org/10.1007/s11165016-9602-2

77. Tecnológico Nacional de México, Anuario Estadístico, 2018, available at https://www.tecnm.mx/pdf/ANUARIO_ESTADI STICO_2018.pdf

78. Tecnológico Nacional de México-Secretaría Académica de Investigación e Innovación, Matemáticas Discretas, 2016, available at http://www.itesi.edu.mx/oferta_academica/nivel_ superior/Pag\%20ISC/pdf/plan_estudios/1\%20Matematicas\% 20Discretas.pdf

79. A. Teemant et al., Modeling sociocultural pedagogy in distance education, Teach. Coll. Rec. 107 (2005), no. 8, 1675-1698.

80. A. Tenev et al., Machine learning approach for classification of ADHD adults, Int. J. Psychophysiol. 93 (2014), no. 1, 162-166. https://doi.org/10.1016/j.ijpsycho.2013.01.008

81. N. T. Thai, B. de Wever, and M. Valcke, The impact of a flipped classroom design on learning performance in higher education: Looking for the best "blend" of lectures and guiding questions with feedback, Comput. Educ. 107 (2017), 113-126. https://doi. org/10.1016/j.compedu.2017.01.003

82. T. Tyrväinen, Prime implicants in dynamic reliability analysis, Reliab. Eng. Syst. Saf. 146 (2016), 39-46. https://doi.org/10. 1016/j.ress.2015.10.007

83. J.van Niekerk and P. Webb, The effectiveness of braincompatible blended learning material in the teaching of 
programming logic, Comput. Educ. 103 (2016), 16-27. https:// doi.org/10.1016/j.compedu.2016.09.008

84. J. Vassileva, Motivating participation in social computing applications: A user modeling perspective, User Model User-Adap. 22 (2012), no. 1-2, 177-201. https://doi.org/10.1007/s11257011-9109-5

85. Y. Wang et al., Let them play: The impact of mechanics and dynamics of a serious game on student perceptions of learning engagement, IEEE Trans. Learn. Technol. 10 (2017), no. 4, 514-525. https://doi.org/10.1109/TLT.2016.2639019

86. A. S. Wilson and J. E. McDonagh, A gamification model to encourage positive healthcare behaviors in young people with long term conditions, EAI Endor. Trans. Ser. Gam. 1 (2014), no. 2, e3. https://doi.org/10.4108/sg.1.2.e3

87. C. Wohlin, P. Runeson, M. Host, M. C. Ohlsson, B. Regnell, and A. Wesslen, Experimentation in software engineering: An introduction, Springer, New York, NY, 2012.

88. F. A. Zampirolli et al., Evaluation process for an introductory programming course using blended learning in engineering education, Comput. Appl. Eng. Educ. 26 (2018), 2210-2222. https://doi.org/10.1002/cae.22029

89. X. Zeng et al., The construction and online/offline blended learning of small private online courses of principles of chemical engineering, Comput. Appl. Eng. Educ. 26 (2018), 1519-1526. https://doi.org/10.1002/cae.22044

\section{AUTHOR BIOGRAPHIES}

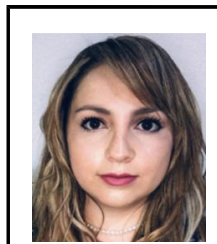

Eréndira M. Jiménez-Hernández was born in Tlaxcala, Mexico in 1987. She received an MSc degree in Computer Science from the National Polytechnic Institute (IPN). She is currently studying for a $\mathrm{PhD}$ in Computer Science at the National Autonomous University of Mexico (UNAM).

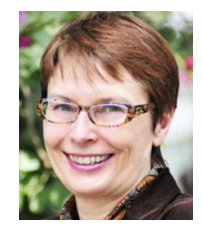

Hanna Oktaba was born in Warsaw, Poland in 1951. She received her PhD in Computer Science from the University of Warsaw. She directed the MoProSoft project, which was published as a Mexican standard (MNX-I-059-NYCE) in 2005. Since 2006, she has been the representative of Mexico in
WG 24 of ISO JTC1/SC7 Software and System Engineering for the creation of the ISO/IEC 29110 standard for Very Small Entities (VSEs). She is a Full Professor at the National Autonomous University of Mexico (UNAM), where she is the leader of the KualiKaans Research Group.

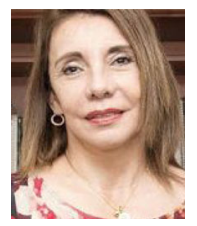

Frida Díaz-Barriga was born in Mexico City, Mexico in 1955. She received her $\mathrm{PhD}$ in Pedagogy from the National Autonomous University of Mexico (UNAM). In 2005, she received the “Sor Juana Inés de la Cruz Medal” for her outstanding professional career. In 2009, she received the Mexican Award for Psychology. She is level III member of the National System of Researchers in Mexico. She is a Full Professor at the UNAM, where she is the leader of the GIDDET Research Group.

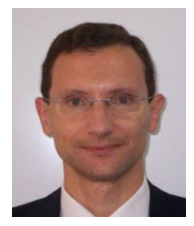

Mario Piattini was born in Buenos Aires, Argentina in 1966. He received his MSc degree and his PhD in Computer Science from the Polytechnic University of Madrid (UPM) and his MSc degree in Psychology from the UNED. In 2016, He received the Aritmel Award, for having made outstanding scientific contributions in the area of Computer Engineering. He is a Full Professor at the University of Castilla-La Mancha (UCLM), where he is the leader of the Alarcos Research Group.

How to cite this article: Jiménez-Hernández EM, Oktaba H, Díaz-Barriga F, Piattini M. Using webbased gamified software to learn Boolean algebra simplification in a blended learning setting. Comput Appl Eng Educ. 2020;1-21. https://doi.org/10.1002/cae.22335 


\section{APPENDIX A: QUESTIONNAIRE TO \\ $2=$ Slightly true \\ EVALUATE THE MOTIVATION \\ $3=$ Moderately true \\ Evaluation scale \\ $4=$ Mostly true \\ $5=$ Very true}

$1=$ Not true

Question
Attention
1. When I started learning to simplify Boolean functions, there was something
interesting that attracted my attention.
4. When I was learning to simplify Boolean functions, there was very little in the
learning activities that attracted my attention. (Reverse)
10. The educational materials were very attractive.
15. I discovered interesting facts regarding the simplification of Boolean functions.
21. The professor did unusual or surprising things that were interesting.
24. The professor used an interesting variety of teaching techniques.
26. I tended to daydream while I was learning to simplify Boolean functions. (Reverse)
29. My curiosity was often stimulated by the questions asked or the problems
provided in relation to the simplification of Boolean functions.
Average of attention

Relevance

2. The fact of having learned to simplify Boolean functions will be useful for me.

5. After learning to simplify Boolean functions I became aware of their educational relevance.

8. I do not see how the simplification of Boolean functions relates to anything I already know. (Reverse)

13. The simplification of Boolean functions is very relevant as regards understanding other subjects.

20. The simplification of Boolean functions relates to my expectations and goals.

22. The simplification of Boolean functions is very practical for me.

$\frac{\text { Control group }}{\overline{\boldsymbol{x}} \quad \begin{array}{l}\text { Standard } \\ \text { deviation }\end{array}}$

Experimental

group

$\overline{\boldsymbol{x}} \quad$ deviation

23. The simplification of Boolean functions motivates me to study them.

3.39

0.62

3.23

0.43

3.40

0.60

0.44

0.60

3.30

3.42

3.35

3.42

0.50

0.61

0.50

3.34

0.41

3.39

3.26

0.56

0.44

3.68

3.55

0.65

3.29

0.53

3.55

0.51

3.10

0.40

3.48

0.51

3.42

3.10

0.62

3.65

0.55

0.40

3.48

0.51

3.39

0.62

3.65

0.55

25. I do not think I will benefit much from learning to simplify Boolean functions. (Reverse)

28. The personal benefits of learning to simplify Boolean functions are clear to me.

3.10

0.40

3.42

0.50

3.19

0.48

3.55

0.51

3.25

0.32

3.56

0.38

\section{Confidence}

3. It was easy to learn the simplification of Boolean functions.

6. You have to be lucky to get good grades in the Boolean algebra unit. (Reverse)

9. The educational content of the Boolean algebra unit has a well-organized

11. The simplification of Boolean functions was just too difficult for me. (Reverse)

17. It was difficult to predict what grade the teacher would give my assignments. (Reverse)

30. I found the level of challenge as regards learning the simplification of Boolean

34. When I was learning to simplify Boolean functions, I got enough feedback to

know how well I was doing.

Average of confidence 


\section{Satisfaction}

7. I had to work too hard to succeed in learning to simplify Boolean functions. (Reverse)

12. I feel that having learned to simplify Boolean functions gave me a lot of satisfaction.

14. I am happy to have successfully completed the activities in the Boolean algebra unit.

16. I enjoyed learning to simplify Boolean functions. thought I had done.

19. I feel satisfied with what I attained after learning to simplify Boolean functions.

31. I feel rather disappointed after learning to simplify Boolean functions. (Reverse)

32. I feel that I got enough recognition of my work in this unit by means of grades, comments, or other feedback.

33. The amount of work I did was appropriate to learn to simplify Boolean functions.

Average of satisfaction
3.74

0.68

4.19

0.87

3.74

0.73

3.97

0.91

0.87

3.97

4.39

0.72

0.91

0.79

4.26

0.44

4.03

4.10

.

3.74

0.68

4.77

0.43

4.35

0.49

$4.61 \quad 0.50$

$4.61 \quad 0.50$

4.81

0.40

3.99

0.66 